\title{
MONTAGEM E CARACTERIZAÇÃO ELÉTRICA DE PILHAS A COMBUSTÍVEL DE ÓXIDO SÓLIDO (PaCOS)
}

Hosane Aparecida Tarôco, Samuel Tadeu de Paula Andrade, Márcia Caldeira Brant, Rosana Zacarias Domingues e Tulio Matencio*

Departamento de Química, Instituto de Ciências Exatas, Universidade Federal de Minas Gerais, CP 702, 31270-901 Belo Horizonte - MG, Brasil

Recebido em 7/8/08; aceito em 16/1/09; publicado na web em 11/5/09

\begin{abstract}
ASSEMBLY AND ELECTRICAL CHARACTERIZATION OF SOLID OXIDE FUEL CELL STACKS. This paper is focused on a review of the design features and the electrochemistry characterization of anode-supported planar SOFC. Studies and results of metallic alloy interconnectors and recovery for protection against corrosion and for contact layer are showed. Moreover a discussion of examples of measurements of impedance spectrometry, according to the literature and our experimental results are made. For the anode supported fuel cells the power density varies from 0.1 to $0.5 \mathrm{Wcm}^{2}$, according to results in the literature (showed in this paper). For electrolyte supported fuel cell the power density can be $10 \mathrm{Wcm}^{-2}$ for high temperatures. An English-Portuguese glossary of most used terms in SOFC stack is given for greater clarity and to introduce new terms to the reader.
\end{abstract}

Keywords: SOFC, planar stack, impedance spectrometry.

\section{INTRODUÇÃO}

As pilhas a combustível ( $\mathrm{PaC}$ ) são dispositivos que convertem energia química em energia elétrica, através da reação eletroquímica entre um combustível $\left(\mathrm{H}_{2}\right)$ e um oxidante $\left(\mathrm{O}_{2}\right)$, com mínima emissão de poluentes tóxicos e alta eficiência. ${ }^{1,2}$

Existem 5 tipos de PaC: as alcalinas (AFC) com temperatura de operação entre $60-90{ }^{\circ} \mathrm{C}$, as de membrana polimérica (PEMFC), $80-90{ }^{\circ} \mathrm{C}$, as de carbonato fundido (MCFC), $650-700{ }^{\circ} \mathrm{C}$, as de ácido fosfórico (PAFC), $160-200{ }^{\circ} \mathrm{C}$ e as de óxido sólido (PaCOS), 800-900 ${ }^{\circ} \mathrm{C} .{ }^{3,4}$ Cada célula possui um tipo de eletrólito com temperaturas de operações diferentes, fazendo com que tenham aplicações diversificadas como aeroespaciais, estacionárias ou móveis. ${ }^{4-8}$

O MCT (Ministério de Ciência e Tecnologia) instituiu, em 2002, o ProCaC (Programa Brasileiro de Sistemas de Células a combustível) ${ }^{9}$ permitindo ações integradas e colaboradas, para o desenvolvimento da tecnologia nacional de células a combustível. O programa foi estruturado a partir de redes cooperativas P\&D dentre elas: Rede de Células a Combustível de membranas poliméricas, Rede de Células a Combustível de Óxido Sólido, Rede de Combustíveis e Hidrogênio, Rede de Sistemas e Integração e Rede de Utilização (esta última está em implementação).

No âmbito das Pilhas a Combustível de Óxido Sólido, tema deste artigo a rede é denominada Rede PaCOS, ${ }^{10}$ que visa fomentar o desenvolvimento deste tipo de célula no Brasil e fortalecer os grupos de pesquisa e desenvolvimento destas áreas e outras afins. Neste sentido, uma parceria foi firmada entre várias universidades brasileiras. Dentre elas: Universidade Federal de Minas Gerais (UFMG), Universidade Federal da Bahia (UFBA), Universidade Federal do Rio de Janeiro/ COOPE (UFRJ), Universidade Federal de São Carlos (UFSCAR), Universidade Estadual Paulista (UNESP), Instituto de Pesquisas Energéticas e Nucleares (IPEN), Universidade Federal de Itajubá (UNIFEI), Universidade Federal do Rio Grande do Norte (UFRN), Universidade Federal de Santa Catarina (UFSC), Universidade Estadual do Sudoeste da Bahia (UESB) e Universidade Estadual do Norte Fluminense (UENF).

*e-mail: tmatencio@ufmg.br
Nesta revisão será dada ênfase às pilhas a combustível de óxido sólido (PaCOS) que são formadas por empilhamentos de células unitárias constituídas por dois eletrodos porosos cerâmicos (anodo e catodo) e por um eletrólito cerâmico denso e condutor iônico. Serão discutidos também de forma mais detalhada, os interconectores (cerâmicos ou metálicos) que são os dispositivos responsáveis pelo contato elétrico entre as células unitárias e a distribuição dos gases nos eletrodos das PaCOS.

Durante o funcionamento das $\mathrm{PaCOS}$, o $\mathrm{O}_{2}$ é introduzido, em cada célula unitária, pelos catodos e reduzido a $\mathrm{O}^{2-}$. Através dos anodos, o $\mathrm{H}_{2}$ entra nas células e é oxidado a $\mathrm{H}^{+}$. Os íons $\mathrm{O}^{2-}$ deslocam-se pelos eletrólitos até as interfaces eletrólito/anodo onde reagem com $\mathrm{H}^{+}$, formando $\mathrm{H}_{2} \mathrm{O}$, um dos produtos da reação da pilha, conforme mostrado na Figura 1. Os elétrons gerados pela oxidação do combustível são conduzidos do anodo para o catodo através do circuito externo, gerando corrente elétrica.

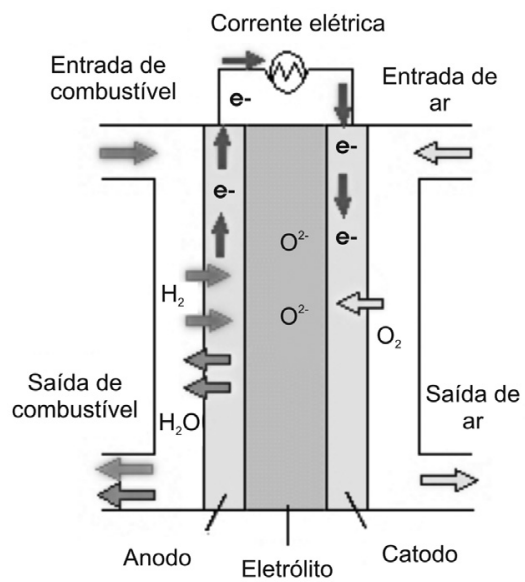

Figura 1. Esquema de funcionamento de uma célula a combustível do tipo óxido sólido. Adaptada ref. 8

Atualmente várias companhias e institutos de pesquisas trabalham na área das PaCOS, investigando configurações e diferentes materiais. ${ }^{11}$

$\mathrm{O}$ potencial em circuito aberto de cada célula unitária de uma 
PaCOS é da ordem de 1,1-1,2 V, podendo chegar a menos de $0,8 \mathrm{~V}$ durante o funcionamento. Assim, para gerar uma maior potência, é necessário realizar o empilhamento destas células. Com a associação de várias células unitárias, em série ou paralelo, é possível obter dispositivos energéticos com potências variando da ordem de algumas dezenas de $\mathrm{kW}$ até centenas de MW, por exemplo. ${ }^{11}$ Este empilhamento pode ser realizado com configurações planar, tubular ou monolítica, sendo a primeira a mais comum atualmente.

Recentemente, a revista Química Nova deu um espaço importante para a divulgação do Estado da Arte das PaCOS em termos tecnológicos, com algumas publicações relevantes, dentre elas: a de Amado e colaboradores, ${ }^{2}$ que apresenta materiais, componentes e configurações das PaCOS. Nesse trabalho, os autores abordaram alguns conceitos fundamentais relacionados às pilhas a combustível como os tipos existentes, as características e os princípios de funcionamento. Aspectos mais detalhados sobre os materiais utilizados nas PaCOS (anodo, catodo e eletrólito), tipos de interconectores e selantes e métodos de fabricação dos mesmos, bem como a configuração das células também foram abordados por eles.

Florio e colaboradores ${ }^{11}$ publicaram, na mesma revista, um trabalho abordando o cenário atual da PaCOS no sentido da sua comercialização, apontando os principais aspectos tecnológicos que devem ser superados para se chegar a um produto comercialmente competitivo. Através desse trabalho é possível avaliar os principais aspectos tecnológicos das $\mathrm{PaCOS}$ quando colocadas à prova nas condições mais próximas do uso prático, como as situações de testes de campo por longos períodos de tempo, visando sua competitividade comercial.

Cabe também ressaltar outros trabalhos ${ }^{12,14}$ que foram publicados na revista Química Nova e que são relacionados às pilhas a combustível de baixas temperaturas, dentre eles: o trabalho de Wendt e colaboradores, ${ }^{12}$ que mostra aspectos importantes de eletrocatálise e eletrocalisadores para essas células. Nele são abordados os fundamentos, o estado da arte e as pesquisas aplicadas ao desenvolvimento de metais nobres como catalisadores utilizados em células a combustível de baixas temperaturas.

Entretanto, devido à complexidade, multidisciplinaridade e extensão do assunto, decidimos apresentar uma revisão focalizada na tecnologia de stacks (pilhas) propriamente dita e na concepção, realização e interpretação das medidas eletroquímicas associadas a estes dispositivos, esperando que este texto possa ser especialmente útil para professores, alunos e pesquisadores interessados em aspectos experimentais do tema. No final do artigo é fornecido um glossário em inglês-português contendo os termos mais empregados na área de empilhamento das PaCOS, visando proporcionar maior clareza ao texto e introduzir termos relativamente novos ao leitor.

\section{INTERCONECTORES}

Dentre as funções do interconector destacam-se: separar fisicamente o catodo e anodo das células unitárias, conectar eletricamente o anodo de uma célula unitária ao catodo da outra, distribuir os gases nas superfícies dos eletrodos..$^{15}$
O interconector é um componente que exige rigorosos requisitos ${ }^{1}$ nas condições de operação da PaCOS, tais como alta condutividade elétrica; estabilidade química, dimensional e estrutural, sob atmosferas oxidantes e redutoras; coeficiente de expansão térmica compatível (CET) com os materiais da célula, desde a temperatura ambiente à temperatura de operação da pilha para evitar tensões mecânicas; ${ }^{16,17}$ estabilidade microestrutural sob gradiente de potencial químico; impermeabilidade ao oxigênio e/ ou hidrogênio ${ }^{1}$ alta condutividade térmica e resistência mecânica em altas temperaturas; baixo custo de fabricação para viabilizar a comercialização das PaCOS.

Entre os materiais pesquisados nas últimas décadas para fabricação de interconectores, destacam-se os óxidos de terras raras do tipo perovskita, como $\mathrm{YCrO}_{3}$ e o $\mathrm{LaCrO}_{3},{ }^{17-19} \mathrm{em}$ que a cromita de lantânio se apresenta como material mais adequado. Vários tipos de dopantes podem ser utilizados, sendo que a natureza e a composição do mesmo exercem influência na condutividade elétrica, no valor de expansão térmica e na resistência mecânica, ${ }^{20,21}$ de acordo com a Tabela 1.

$\mathrm{O}$ alto custo e a baixa plasticidade inerente aos materiais cerâmicos levaram os pesquisadores a procurar materiais mais baratos como as ligas metálicas do tipo aços inoxidáveis ${ }^{17,19,22-24}$ e outras à base de níquel, principalmente do tipo "Inconel"24-27 e a Haynes $230 .^{28}$ Essas ligas podem substituir os interconectores cerâmicos quando são utilizados eletrólitos de menor espessura que permitem temperaturas de trabalho da ordem de $800^{\circ} \mathrm{C}$. Um dos aços inoxidáveis de menor custo é o "AISI 430". ${ }^{24,29-38}$ Percebe-se que a degradação dos aços e a diferença entre o CET destes e dos demais materiais da célula são os principais problemas enfrentados no empilhamento. Assim, novos tipos de aços inoxidáveis foram desenvolvidos na tentativa de se obter materiais que possuam CET próximo aos demais componentes e que resistam às condições de operação da pilha. Duas ligas que exemplificam bem esta tentativa são "Crofer 22 APU"23,32-34 e "Hitachi ZMG 232". ${ }^{35}$

O fato dos interconectores metálicos possuírem um coeficiente de expansão térmica maior que os demais componentes da célula, e estarem expostos à atmosfera oxidante e redutora, faz que estes materiais estejam sujeitos à maior tendência à oxidação e tensões mecânicas. Para minimizar os efeitos da corrosão aplica-se em geral uma camada protetora de baixa resistência ôhmica e que possua CET compatível com os outros componentes da célula, Tabela 2.

Em ligas contendo cromo e/ou alumínio quando em contato com o meio corrosivo, em geral, se passivam devido à formação de uma camada de $\mathrm{Cr}_{2} \mathrm{O}_{3}$ (óxido de Cromo III) ou $\mathrm{Al}_{2} \mathrm{O}_{3}$ (óxido de Alumínio III) que protege o material contra a corrosão, sendo que a eficiência desta camada é dependente da composição de $\mathrm{Al}$ e $\mathrm{Cr}$ presente na liga. ${ }^{18,36}$ No entanto, a camada de $\mathrm{Cr}$ pode afetar o desempenho da célula, devido à evaporação de espécies gasosas do tipo $\mathrm{Cr}^{6+}$ que podem interagir com o catodo e formar nas interfaces catodo/eletrólito, novas fases indesejáveis como $(\mathrm{CrMn})_{3} \mathrm{O}_{4}$ (óxido duplo de $\mathrm{Cr}$ e $\mathrm{Mn}$ ) ou $\mathrm{Cr}_{2} \mathrm{O}_{3}$, diminuindo a condutividade elétrica do material. ${ }^{18,25,36-38}$

Outro problema apresentado pelos interconectores metálicos

Tabela 1. Condutividade elétrica, coeficiente de expansão térmica e resistência mecânica do $\mathrm{LaCrO}_{3}$ de acordo com alguns dopantes. Adaptada da ref. 22

\begin{tabular}{lcccc}
\hline Interconectores cerâmicos & $\mathrm{LaCrO}_{3}$ & $\mathrm{LaCr}_{0.9} \mathrm{Mg}_{0.1} \mathrm{O}_{3}$ & $\mathrm{La}_{0.9} \mathrm{Sr}_{0.1} \mathrm{Cr}_{3}$ & $\mathrm{La}_{0.8} \mathrm{Ca}_{0.2} \mathrm{Cr}_{0.9} \mathrm{Co}_{0.1} \mathrm{O}_{3}$ \\
\hline Condutividade elétrica a $1000{ }^{\circ} \mathrm{C}\left(\mathrm{S} \mathrm{cm}^{-1}\right)$ & 1 & 3 & 35 & 34 \\
Coeficiente de expansão térmica $\left(\mathrm{x} 10^{-6} \mathrm{~K}^{-1}\right)$ & 9,5 & 9,5 & 10,7 & 11,1 \\
Resistência mecânica a $25^{\circ} \mathrm{C}(\mathrm{MPa})$ & - & $390-418$ & 245 & $100-150$ \\
Resistência mecânica a $1000^{\circ} \mathrm{C}(\mathrm{MPa})$ & - & - & $77(\mathrm{em}$ ar $)$ & $20-60(\mathrm{em}$ ar) \\
\hline
\end{tabular}


Tabela 2. Recobrimentos aplicados em ligas metálicas para minimizar a corrosão

\begin{tabular}{|c|c|c|}
\hline Interconectores metálicos & Recobrimentos & Condições de ensaio* \\
\hline AISI 43029 & Co e óxidos à base de Co & $800^{\circ} \mathrm{C} / \mathrm{ar}$ com $3 \%$ de umidade por $1900 \mathrm{~h}$ \\
\hline AISI 430 e Fecralloy ${ }^{30}$ & LSM & $750^{\circ} \mathrm{C} /$ ar por $2600 \mathrm{~h}$ \\
\hline $\begin{array}{l}\text { DIN 1.4016; DIN 1.4742; DIN 1.4509; DIN } \\
\text { 1.4749; ZMG 232; } \text { Crofer }^{32}\end{array}$ & LMC, LSC, LSMC; YCM & 200 a $850{ }^{\circ} \mathrm{C}$ e $750{ }^{\circ} \mathrm{C}$ por $2100 \mathrm{~h}$ \\
\hline DIN 1.4509; DIN 1.4749; ZMG 232; Crofer ${ }^{34}$ & LMC, LSMC; YCM & $800^{\circ} \mathrm{C} / \mathrm{ar}$ a $2420 \mathrm{~h}$; ciclos térmicos até $3000 \mathrm{~h}$ \\
\hline AISI $444^{39}$ & LSM & $500-850{ }^{\circ} \mathrm{C} ; 800{ }^{\circ} \mathrm{C}$ até $160 \mathrm{~h}$ \\
\hline AISI $430^{40}$ & $\mathrm{MnCo}_{2} \mathrm{O}_{4}$ & 600 a $800^{\circ} \mathrm{C} / \mathrm{ar}$ \\
\hline-31 & $\mathrm{Mn}_{\mathrm{x}} \mathrm{Cr}_{3-\mathrm{x}} \mathrm{O}_{4}(0.5 \leq \mathrm{x} 42.5), \mathrm{NiCr}_{2} \mathrm{O}_{4}$ e $\mathrm{CoCr}_{2} \mathrm{O}_{4}$ & 315 a $900{ }^{\circ} \mathrm{C}$ \\
\hline AL $453^{41}$ & Haynes 230 & $800{ }^{\circ} \mathrm{C} / \mathrm{ar}+3 \%$ de umidade por $300 \mathrm{~h}$ \\
\hline AISI $430^{42}$ & $\mathrm{Co} / \mathrm{LaCrO}_{3}$ & $800^{\circ} \mathrm{C} /$ ar estático por 170 ou $2040 \mathrm{~h}$ \\
\hline Crofer 22 APU, E-Brite, IT-11, F18TNb ${ }^{43}$ & MCF/LSCF & $800^{\circ} \mathrm{C} /$ ar por até $1000 \mathrm{~h}$ \\
\hline
\end{tabular}

* Medidas de resistência ôhmica e/ou REA. AISI: American Iron and Steel Institute, DIN: Deutsches Institut für Normung, AL - Allegheny Ludlum, E-Brite - Liga metálica ferrítica produzida pela empresa americana Allegheny Ludlum, IT -11 - Liga metálica ferrítica produzida pela empresa austríaca Plansee AG, F18TNb - Liga metálica ferrítica produzida pela empresa francesa Ugine Arcelor. Alguns materiais utilizados no recobrimento de interconectores: $\mathrm{LSM}\left(\mathrm{La}_{0,85} \mathrm{Sr}_{0,15} \mathrm{MnO}_{3}\right), \mathrm{LMC}\left(\mathrm{LaMn}_{0,57} \mathrm{Co}_{0,43} \mathrm{O}_{3-\delta}\right), \mathrm{LSC}\left(\mathrm{La}_{0,8} \mathrm{Sr}_{0,2} \mathrm{CoO}_{3-\delta}\right), \mathrm{LSMC}\left(\mathrm{La}_{0,8} \mathrm{Sr}_{0,27} \mathrm{Co}_{0,5} \mathrm{O}_{3-\delta}\right)$; $\mathrm{YCM}\left(\mathrm{Y}_{0,3} \mathrm{Ca}_{0,7} \mathrm{MnO}_{3-\delta}\right), \mathrm{MCF}\left(\mathrm{MnCo}_{1,9} \mathrm{Fe}_{0,1} \mathrm{O}_{4}\right)$

é a formação de camadas de óxidos de ferro na interface selante/ interconector, ${ }^{37} \mathrm{em}$ virtude da interação existente entres os materiais e o combustível, que contribui também para diminuição do desempenho da célula.

Além disso, um fator que deve ser observado é a permeabilidade dos aços ao hidrogênio a altas temperaturas. Efetivamente, como os espaços intersticiais dos aços são relativamente grandes, quando comparados ao tamanho da molécula de hidrogênio, esta é capaz de atravessar o interconector em direção ao catodo causando, assim, microcombustão no lado catódico, além da ocorrência da fragilização da estrutura do aço.

A resistência específica por área (REA - Area Specific Resistance) também é importante para se avaliar o desempenho da célula unitária e da PaCOS visto que, em alguns casos, a densidade de potência de cada célula no empilhamento é menor que a da célula unitária, devido à presença de REA ou de polarização. ${ }^{26,33}$ A REA pode ser expressa como:

$\mathrm{REA}=\frac{E m-E_{N}}{i}$

onde: Em é o potencial medido nas condições de operação da pilha, $\mathrm{E}_{\mathrm{N}}$ é o potencial de Nernst e i é a densidade de corrente.

A REA possui uma contribuição ôhmica (Roh), incluindo a resistência ôhmica do eletrólito, dos eletrodos, a resistência de contato entre estes e o eletrólito, e entre os eletrodos e o coletor de corrente e outra de polarização relacionada aos eletrodos (Rp). Esta é dividida em vários tipos de contribuições devido aos processos eletroquímicos que estão ocorrendo nos TPB (região de contato triplo, onde se encontram o eletrodo, o gás e o eletrólito). ${ }^{22}$ Assim, a REA pode ser definida como:

$\mathrm{REA}=\mathrm{R}(\mathrm{el})+\mathrm{R}(\mathrm{c})+\mathrm{R}(\mathrm{p}$, eletroq $)+\mathrm{R}(\mathrm{p}$, dif $)+\mathrm{R}(\mathrm{p}$, conv $)$

onde: $\mathrm{R}(\mathrm{el})$ é a resistência do eletrólito; $\mathrm{R}(\mathrm{c})$ é a resistência de contato; $\mathrm{R}$ (p, eletroq) é a resistência devida aos processos químicos e eletroquímicos que acontecem na superfície do eletrodo, no bulk do material ou na interface eletrodo/eletrólito, tornando-se etapas limitantes; $R$ (p, dif) é a resistência de polarização relacionada à difusão do gás e $\mathrm{R}$ ( $\mathrm{p}$, conv) é relacionada com a redução do $\mathrm{O}_{2}$ e/ou oxidação do $\mathrm{H}_{2}$.

A REA é influenciada pela espessura e porosidade dos filmes que compõem a célula; ela diminui com o aumento da porosidade do anodo e aumenta com a diminuição da temperatura e com o crescimento da espessura dos filmes. ${ }^{33}$

Outro aspecto importante em relação ao interconector é sua geometria. Em 2002 Tanner e colaboradores ${ }^{45}$ desenvolveram um método analítico de predizer a REA de interconectores, em função dos seus parâmetros geométricos e elétricos. Assim é possível determinar os valores destes parâmetros de forma a minimizar a REA. Já Gubner e colaboradores,${ }^{33} \mathrm{em} 2006$, desenvolveram um método gráfico para predizer a perda de carga ao longo do interconector a partir do uso do método de volumes finitos. Também analisaram a REA, o potencial eletrostático e a densidade de corrente com o uso do método de elementos finitos (FEM).

\section{CONFIGURAÇÕES DAS PaCOS}

A configuração do empilhamento das células unitárias pode ser planar, tubular ${ }^{22,46,47}$ ou monolítica. ${ }^{6,48}$ Em cada configuração, o caminho percorrido pela corrente, a configuração do fluxo dos gases e a forma de distribuição dos mesmos podem variar e influenciar o desempenho da pilha. Aqui só a configuração plana será abordada.

A configuração planar pode ser de dois tipos: com suporte interno (self supporting) ou externo (external supporting). ${ }^{11,49} \mathrm{~A}$ Tabela 3 apresenta algumas vantagens e/ou desvantagens de cada configuração.

Os interconectores possuem vários canais (flow channels) e aletas (fins) que são dimensionados de forma a tornar a distribuição de vazão mais homogênea possível e reduzir a REA e a queda de pressão ao longo do escoamento dos gases. O fluxo destes pode ser do tipo cruzado, paralelo de mesmo sentido, paralelo de sentido contrário (cross-flow, co-flow e counter-flow, respectivamente), serpentina, radial, espiral e no formato $\mathrm{Z}$, sendo os três primeiros os mais comuns. , $^{6,11,22}$

Os distribuidores de vazão (manifold), regiões do interconector ou do sistema que conduz o fluxo dos gases da entrada até os canais de fluxo, também devem ser otimizados na configuração planar. ${ }^{11}$

As principais regras que devem ser respeitadas na elaboração do empilhamento são: otimização dos fluxos de gases, diminuição das tensões mecânicas, melhoria dos contatos entre interconectores e 
Tabela 3. Características das configurações de uma célula unitária

\begin{tabular}{|c|c|c|c|}
\hline Configuração da célula & $\begin{array}{c}\text { Faixa de espessura dos } \\
\text { substratos * }\end{array}$ & Vantagens & Desvantagens \\
\hline Suportada pelo eletrólito ${ }^{50}$ & $\sim 1500 \mu \mathrm{m}$ & $\begin{array}{l}\text { Alta resistência mecânica e } \\
\text { menor tendência a fraturas. }\end{array}$ & $\begin{array}{l}\text { Alta resistência ôhmica do eletrólito e } \\
\text { altas temperaturas de operação. }\end{array}$ \\
\hline Suportada pelo anodo ${ }^{19,24,26,51,52}$ & $1000-2500 \mu \mathrm{m}$ & $\begin{array}{l}\text { Alta condutividade elétrica, } \\
\text { baixa temperatura de operação e } \\
\text { reforma interna do combustível. }\end{array}$ & $\begin{array}{l}\text { Limitação pelo transporte de massa de } \\
\qquad \mathrm{H}_{2} \text { no anodo. }\end{array}$ \\
\hline Suportada pelo catodo ${ }^{53 * *, 54-56}$ & $1000-2000 \mu \mathrm{m}$ & Baixa temperatura de operação. & $\begin{array}{l}\text { Baixa condutividade elétrica do catodo } \\
\text { e limitação pelo transporte de massa de } \\
\qquad \mathrm{O}_{2} \text { no catodo. }\end{array}$ \\
\hline $\begin{array}{l}\text { Suportada por um substrato } \\
\text { poroso (metálico) })^{57 * *}\end{array}$ & $200-300 \mu \mathrm{m}$ & $\begin{array}{l}\text { Componentes da célula com es- } \\
\text { pessura fina e baixa temperatura } \\
\text { de operação. }\end{array}$ & $\begin{array}{l}\text { Diminuição do potencial devido à su- } \\
\text { perfície irregular de substrato metálico } \\
\text { e aumento da resistência ôhmica. }\end{array}$ \\
\hline
\end{tabular}

*Valores retirados das referências citadas nesta tabela. **Artigos que apresentam simulações do comportamento das células unitárias

eletrodos, escolha de materiais para os interconectores que possuam maior resistência à corrosão e baixo custo.

A Figura 2 mostra o esquema de um empilhamento plano de células suportadas pelo anodo na qual uma placa auxiliar para vedação de gases (gasket) é colocada entre a célula unitária e o interconector. Este é um protótipo de $\mathrm{PaCOS}$, em desenvolvimento no LaMPaC (Laboratório de Materiais e Pilhas a Combustível, UFMG), constituído por duas células unitárias suportadas pelo anodo, utilizando interconectores metálicos.

Malhas de Inconel são geralmente usadas para melhorar os contatos elétricos nas interfaces interconector/catodo e interconector/ anodo. ${ }^{24,26}$ Estas malhas podem ser recobertas com pasta de prata e manganita de lantânio dopada com estrôncio (Ag/LSM) para minimizar o risco de oxidação dos interconectores.

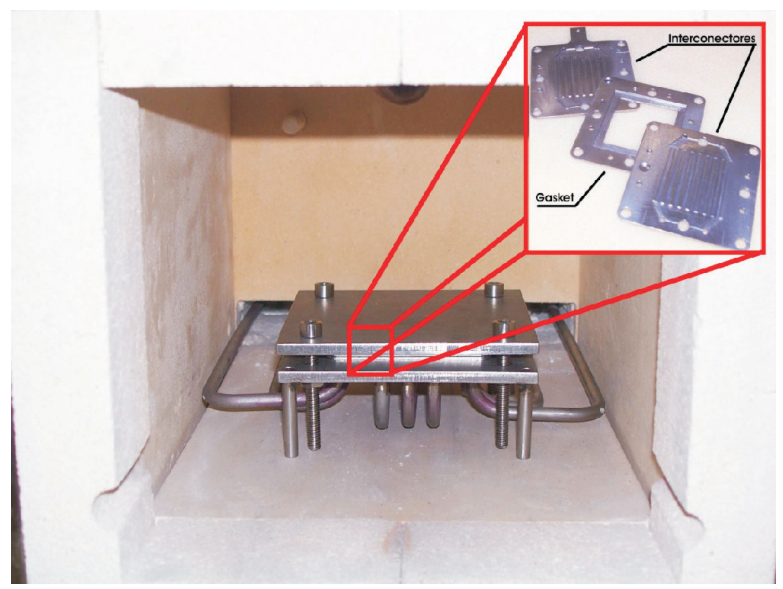

Figura 2. Foto de uma PaCOS suportada pelo anodo, em construção no LaMPaC

\section{CARACTERIZAÇÃO ELÉTRICA}

O estudo do desempenho de uma PaCOS é realizado através da sua caracterização elétrica. Em condições de operação (fora do equilíbrio), a diminuição do seu potencial ocorre devido às perdas de polarização provenientes do transporte de massa (ou concentração), da ativação e da queda ôhmica. ${ }^{22,58}$ Estes fenômenos são devidamente identificados e quantificados através das medidas elétricas de meia célula, ${ }^{59}$ da célula unitária ${ }^{27,60,61}$ e da pilha. ${ }^{19,24,26,33,50-52}$

Durante as medidas elétricas alguns parâmetros podem ser va- riados, como fluxo do $\mathrm{O}_{2}$ ou $\mathrm{H}_{2}$, tempo e temperatura de operação da célula. ${ }^{24,26,50,52}$ As curvas de densidade de potência e potencial em função da densidade de corrente são relevantes para o estudo do desempenho da pilha. Os valores de densidade de potência máxima, para células unitárias suportadas pelo anodo, segundo alguns autores, podem variar desde 0,18 até $10 \mathrm{~W} \mathrm{~cm}^{-2},{ }^{26,50}$ conforme exemplos da Tabela 4. As variações observadas podem estar relacionadas com o tipo e a microestrutura dos componentes da pilha, a temperatura, o fluxo dos gases durante a operação e o número de células unitárias utilizadas no empilhamento.

Para a realização das medidas de desempenho elétrico da célula unitária ou da pilha, dois tipos de equipamentos são em geral empregados: i) os potenciostatos/galvanostatos. Como os potenciostatos comuns trabalham com correntes relativamente baixas (inferiores a 2 A) é necessário utilizar amplificadores de corrente; ii) as estações de testes de PaCOS, ${ }^{62}$ que são equipamentos desenvolvidos especialmente para a avaliação do desempenho elétrico das pilhas e o controle da temperatura e dos fluxos de gases durante o funcionamento das mesmas. A principal vantagem das estações de testes é a integração dos sistemas de controle e a facilidade de aquisição dos parâmetros térmicos, hidrodinâmicos e elétricos da pilha.

$\mathrm{Na}$ alternativa potenciostato/galvanostato os controles dos fluxos de gases e da temperatura da PaCOS são realizados por dispositivos independentes. Com esta opção é possível também realizar a caracterização eletroquímica das células unitárias da PaCOS, empregando uma montagem com 3 eletrodos (trabalho, referência e contra eletrodo) e utilizando as células unitárias como células eletroquímicas.

Outra técnica bastante empregada para caracterizar o comportamento elétrico e eletroquímico das PaCOS é a espectroscopia de impedância eletroquímica (EIE) ${ }^{62,63}$ que consiste na análise da evolução da impedância, $\mathrm{Z}(f)$, da $\mathrm{PaCOS}$ ou das células unitárias em função de uma perturbação alternativa, de frequência variável $f$, em corrente, $\mathrm{I}(f)$, ou em potencial, $\mathrm{E}(f)$. A impedância é um numero complexo dividido em uma parte real $Z_{\text {real }}(f)$ e outra imaginária $Z_{\text {im }}(f)$ :

$$
\mathrm{Z}(f)=\mathrm{Z}_{\text {real }}(f)+\mathrm{j} \mathrm{Z}_{\mathrm{im}}(f)=\frac{\mathrm{E}(f)}{\mathrm{I}(f)}
$$

com o número complexo $\mathrm{j}=(-1)^{1 / 2}$.

As representações gráficas da impedância são geralmente realizadas nos formatos Nyquist ou Bode. Na representação de Nyquist, a mais empregada pelos eletroquímicos e também conhecida como Argand ou Cole-Cole, é expressa - $\operatorname{Zim}(f)$ em função do Zreal $(f)$. A 
Tabela 4. Dados experimentais utilizados por alguns autores na construção das PaCOS com anodo e eletrólito do tipo ZEI/NiO e ZEI, respectivamente (com exceção da referências em negrito). Todas as células unitárias são suportadas pelo anodo, com exceção da ref. 50

\begin{tabular}{|c|c|c|c|c|c|c|}
\hline Ref & $\mathrm{N}_{\mathrm{c}}^{*}$ & Interconector & Selante & Catodo & $\mathrm{T}\left({ }^{\circ} \mathrm{C}\right)$ & $\mathrm{DP} * *\left(\mathrm{~W} / \mathrm{cm}^{2}\right)$ \\
\hline 26 & 3 & Inconel & Vitro-cerâmico & LSM/LSM-YSZ & 750 & 0,43 \\
\hline \multirow{2}{*}{24} & 15 & Inconel & Borosilicato & LSM & 750 & $0,18-0,26$ \\
\hline & 5 & AISI 430 & Borosilicato & LSCF & $650-750$ & $0,18-0,27$ \\
\hline \multirow{2}{*}{19} & 7 & Aço inox & Vitro-cerâmico & LSM & 750 & - \\
\hline & 20 & Aço inox & Vitro-cerâmico & LSM & 750 & $200^{* * *}$ \\
\hline 33 & 2 & Crofer 22 APU & Vitro-cerâmico & LSM/YSZ & 800 & 0,5 \\
\hline \multirow{2}{*}{50} & 10 & $\begin{array}{l}\text { Liga metálica à base } \\
\text { de Cromo }\end{array}$ & $\mathrm{SiO}_{2}-\mathrm{Al}_{2} \mathrm{O}_{3}-\mathrm{CaO}$ & $\begin{array}{l}(\mathrm{Pr}, \mathrm{Nd}, \mathrm{Sm})_{1-\mathrm{x}} \\
\mathrm{Sr}_{\mathrm{x}} \mathrm{MnO}_{3}\end{array}$ & 1000 & 0,11 \\
\hline & 80 & $\begin{array}{l}\text { Liga metálica à base } \\
\text { de Cromo }\end{array}$ & $\mathrm{SiO}_{2}-\mathrm{Al}_{2} \mathrm{O}_{3}-\mathrm{CaO}$ & $\begin{array}{l}(\mathrm{Pr}, \mathrm{Nd}, \mathrm{Sm})_{1-\mathrm{x}} \\
\mathrm{Sr}_{\mathrm{x}} \mathrm{MnO}_{3}\end{array}$ & 1000 & 10 \\
\hline \multirow{2}{*}{52} & 5 & Metálico & Não especificado & LSF/LSC & 800 & 0,5 \\
\hline & 5 & Metálico & Não especificado & $\mathrm{LSF} / \mathrm{LSC}$ & 780 & 0,3 \\
\hline 54 & $1-5$ & Metálico & Pasta de vidro & LSM/LSM-YSZ & 800 & $\begin{array}{c}0,149 ; 0,114 \mathrm{e} \\
0,113^{\#}\end{array}$ \\
\hline 55 & 25 e 50 & Aço inoxidável & Não especificado & $\mathrm{LaNi}(\mathrm{Fe}) \mathrm{O}_{3}$ & 800 & 350 e $1120^{* * *}$ \\
\hline
\end{tabular}

*Quantidade de células unitárias do empilhamento. **Densidade de potência da célula unitária. ***Potência gerada pela pilha, em W. \# para as composições de gases de: $2 \mathrm{H}_{2}+3 \% \mathrm{H}_{2} \mathrm{O} / 4 \mathrm{O}_{2}(\mathrm{~L} / \mathrm{min}), 1 \mathrm{H}_{2}+1 \mathrm{~N}_{2}+3 \% \mathrm{H}_{2} \mathrm{O} / 4$ ar e $2 \mathrm{H}_{2}+3 \% \mathrm{H}_{2} \mathrm{O} / 4$ ar, respectivamente.

representação de Bode, muito utilizada pelos eletricistas, consiste em dois gráficos nos quais são representados $\phi(f)=\operatorname{artg} \frac{Z_{\text {im }}(f)}{Z_{\text {real }}(f)}$ e $\log |Z(f)|=\log \sqrt{Z_{\text {real }}(f)^{2}+Z_{\text {im }}(f)^{2}}$ versus $\log f$. Sendo que $|Z(f)|$ é o módulo da impedância e $\phi(f)$ é a defasagem da corrente em relação ao potencial, conhecida como ângulo de fase.

Através da EIE é possível obter informações sobre as perdas individuais que ocorrem nas células, a cinética da reação de redução do gás oxigênio, o transporte de massa e a resistência ôhmica do eletrólito. Em relação ao desempenho das células os efeitos mais estudados, durante as medidas por EIE são de temperatura, de microestrutura, de pressão e de fluxo dos gases. ${ }^{27-29,31,32,34,37,38,64,65} \mathrm{~A}$ evolução da impedância da célula está relacionada com os vários processos físico-químicos que contribuem para sua resistência interna e determinam seu comportamento dinâmico numa determinada faixa de frequência, sendo que cada um destes processos está associado a uma frequência de relaxação específica. Esta dependência com o tempo pode ser descrita em termos de tempos de relaxação (ou constante de tempo) que podem se estender por mais de quinze ordens de grandeza dependendo da velocidade do processo. Devido a limitações de ordem experimentais, a EIE é adaptada para estudo de processos eletroquímicos em que os tempos de relaxação variam de $\mu$ a dezenas de segundos. ${ }^{22}$ Processos eletroquímicos mais lentos, exibindo constante de tempo de vários minutos a centenas de horas, são preferencialmente estudados através de técnicas como voltametria cíclica, cronoamperometria ou cronopotenciometria. ${ }^{22,66}$

Durante a operação da célula, a EIE pode ser empregada para identificar e estudar processos normais de funcionamento, como transporte de cargas, condução iônica e eletrônica, adsorção, dissociação, ionização e difusão do gás, ou processos de degradação devido à adsorção de impurezas dos gases, mudanças microestruturais, corrosão, interdifusão e aglomeração. ${ }^{22}$

A impedância eletroquímica pode ser descrita por circuitos elétricos constituídos de elementos como capacitância (C), indutância (1), resistência (R), Warburg (W) ou elemento de fase constante $(\mathrm{CPE}){ }^{62}$ Sendo $\mathrm{CPE}=1 /(\mathrm{j} \omega \mathrm{Q})^{\mathrm{n}}$, onde $\omega=2 \pi f$ é a frequência angular, Q é uma constante independe da frequência e $\mathrm{n}$ um fator adimensional que geralmente possui um valor entre 0,5 e 1. Estes elementos elétricos são associados em série, paralelo ou numa combinação dos dois.

Para realizar medidas de EIE é necessário acoplar o potenciostato/galvanostato a um impedancímetro ou utilizar um potenciostato/ galvanostato com módulo de impedância integrado, sendo este já existente no mercado.

\section{EXEMPLOS DE ESTUDOS ELÉTRICOS REALIZADOS EM PaCOS}

A seguir serão apresentados e discutidos alguns exemplos de estudos elétricos e eletroquímicos realizados em $\mathrm{PaCOS}$ descritos na literatura e em células unitárias desenvolvidas no LaMPaC.

Na Tabela 4 são mostrados os desempenhos de diferentes PaCOS em função da configuração, dos tipos de materiais e da temperatura de operação, de acordo com alguns autores.

A Figura 3 mostra o desempenho de duas PaCOS de 5 x $5 \mathrm{~cm}^{2}$ (área ativa do catodo de 4,7 X 4,7 $\mathrm{cm}^{2}$ ) desenvolvidas por Bae e colaboradores, ${ }^{24}$ cujos detalhes de materiais e resultados se encontram na Tabela 4. Neste trabalho, dentre outros empilhamentos, foram utilizadas quinze células idênticas suportadas pelo anodo, operando em uma mesma temperatura em diferentes fluxos de gases. A potência da pilha foi de $60 \mathrm{~W}$ (aproximadamente $0,18 \mathrm{~W} \mathrm{~cm}^{-2}$ para cada célula unitária) sob fluxos de $150 \mathrm{~cm}^{3} \mathrm{~min}^{-1}$ de $\mathrm{H}_{2}$ e 300 $\mathrm{cm}^{3} \mathrm{~min}^{-1}$ de ar e $85 \mathrm{~W}$ (aproximadamente $0,26 \mathrm{~W} \mathrm{~cm}^{-2}$ para a célula unitária) sob fluxos de $300 \mathrm{~cm}^{3} \mathrm{~min}^{-1} \mathrm{de}_{2}$ e $450 \mathrm{~cm}^{3} \mathrm{~min}^{-1}$ de ar. No entanto, nas primeiras $300 \mathrm{~h}$, o desempenho sofreu uma diminuição devido à possível oxidação dos interconectores do lado dos catodos e ao aumento das resistências de contato. Após este período o desempenho inicial se restabeleceu e permaneceu estável durante um período de $8000 \mathrm{~h}$ a $750{ }^{\circ} \mathrm{C}$. O potencial de circuito aberto da pilha mostrou-se estável, mas com o aumento da passagem de corrente sofreu alterações devido à possível distribuição não uniforme dos gases nas células unitárias. 


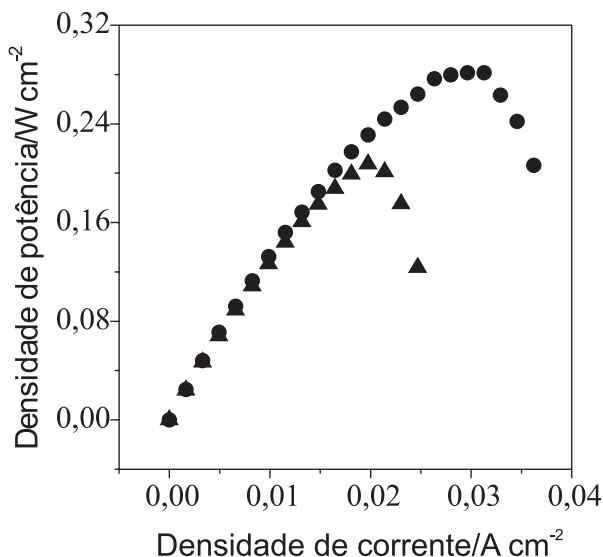

Figura 3. Desempenho de SOFC suportadas pelo anodo. $\bullet: \mathrm{H}_{2} 150 \mathrm{~cm}^{3} \mathrm{~min}^{-1}$ e ar $300 \mathrm{~cm}^{3} \mathrm{~min}^{-1}$ e $\mathbf{\Delta}: \mathrm{H}_{2} 300 \mathrm{~cm}^{3} \mathrm{~min}^{-1}$ e ar $450 \mathrm{~cm}^{3} \mathrm{~min}^{-1}$. Adaptada da ref. 24

Quando as células são suportadas pelo eletrólito, como pode ser ilustrado a partir de medidas realizadas no LaMPaC, Figura 4, o desempenho é bem menor quando comparado com as células suportadas pelo anodo, chegando a atingir uma densidade de potência máxima de $2,5 \mathrm{~mW} \mathrm{~cm}^{-2}$ para uma célula unitária, com fluxos de $\mathrm{H}_{2}$ e ar de 250 e $500 \mathrm{~mL} \mathrm{~min}^{-1}$, respectivamente, a 800 ${ }^{\circ} \mathrm{C}$. Este comportamento é principalmente devido à alta espessura do eletrólito que é uma pastilha de zircônia estabilizada com ítria (ZEI) de 1,5 mm de espessura possuindo, assim, uma alta resistência ôhmica, na temperatura de operação. Nesta célula o anodo é o cermet ZEI/Ni de espessura de, aproximadamente, $50 \mu \mathrm{m}$. A camada funcional do catodo é um compósito de ZEI e manganita de lantânio dopada com estrôncio, $\mathrm{La}_{0,7} \mathrm{Sr}_{0,3} \mathrm{MnO}_{3}$ (LSM/ZEI) com espessura de $30 \mu \mathrm{m}$, enquanto que a camada coletora de corrente (LSM) possui espessura de $90 \mu \mathrm{m}$. Os filmes foram depositados por aerografia e sinterizados a $1400^{\circ} \mathrm{C} / 4 \mathrm{~h}$. O potencial de circuito aberto (OCV) da célula mostrou-se próximo ao teórico, aproximadamente $1,0 \mathrm{~V}$.

Como exemplo de pilha suportada pelo eletrólito, será abordado aqui o trabalho de Wen e colaboradores ${ }^{50}$ que empilhou 10 e 80 células unitárias, Tabela 4. O desempenho obtido para cada célula unitária foi bastante promissor, devido à maior temperatura de funcionamento que favoreceu a cinética da reação, diminuindo a polarização por ativação e a queda ôhmica, Figura 5.

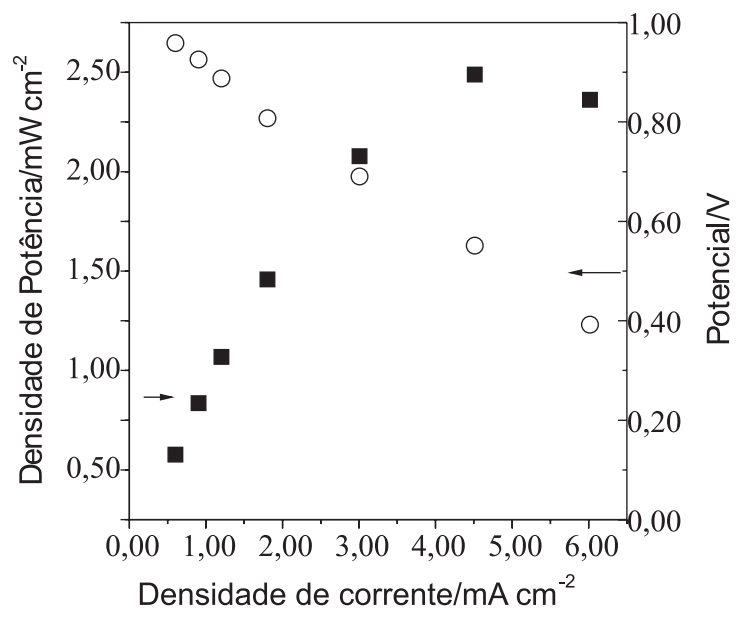

Figura 4. Desempenho de uma célula unitária suportada pelo eletrólito com

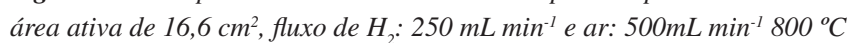

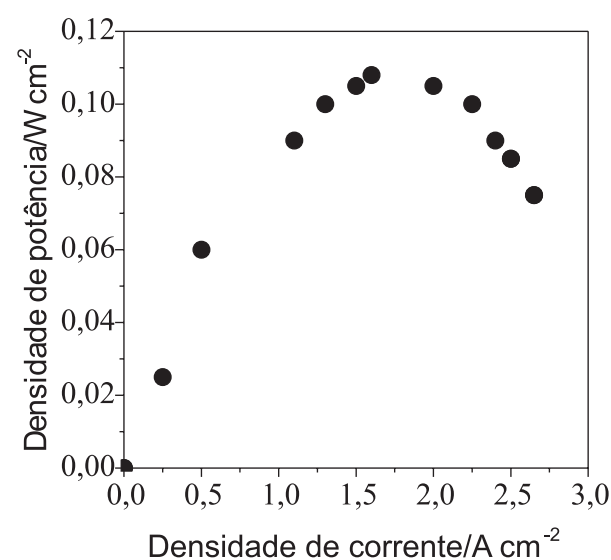

Figura 5. Gráfico do desempenho de uma PaCOS de 10 células de $40 \times 40 \mathrm{~mm}^{2}$ a $1000^{\circ} \mathrm{C}$. Adaptada da ref. 50

\section{EXEMPLOS DE ESTUDOS ELETROQUÍMICOS REALIZADOS EM PaCOS}

Os diagramas do plano de Nyquist para uma célula unitária ou uma pilha, apresentam um, dois ou mais semicírculos, ${ }^{24,27,51,58}$ os quais estão associados a fenômenos eletroquímicos diferentes. A Figura 6 mostra o diagrama de Nyquist da célula unitária suportada pelo eletrólito com área ativa de $16,6 \mathrm{~cm}^{2}$ operando a $800{ }^{\circ} \mathrm{C}$, construída no LaMPaC. As medidas de EIE foram realizadas na faixa de frequência de $10^{-3}$ a $10^{3} \mathrm{~Hz}$ e com uma amplitude do potencial de perturbação de $50 \mathrm{mV}$ utilizando um equipamento Autolab PG100/FRA.

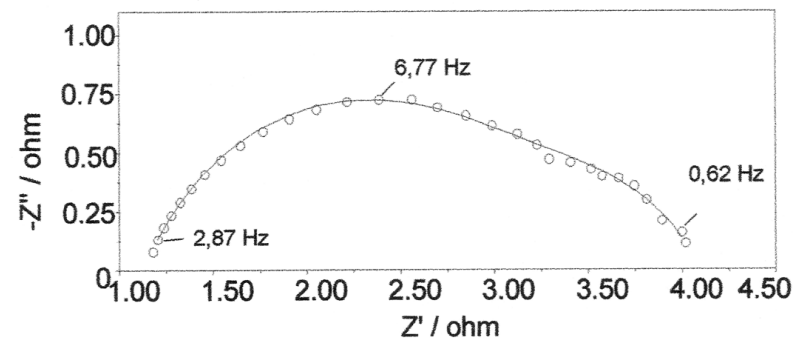

Figura 6. Diagrama de Nyquist de uma célula unitária do tipo óxido sólido suportada pelo eletrólito com $16,6 \mathrm{~cm}^{2}$ de área ativa a $800^{\circ} \mathrm{C}$. Pontos: dados experimentais e curva contínua: ajuste utilizando o circuito equivalente representado na Figura 7

Este diagrama foi analisado utilizando o software Frequency Response Analyser (FRA) ${ }^{67}$ que possibilitou a determinação de um circuito equivalente do comportamento da célula unitária representado na Figura 7, na qual $\mathrm{R}_{1}$ é a resistência ôhmica total (soma das resistências do eletrólito, do eletrodo e do contato da interface catodo/ eletrólito e anodo/eletrólito e dos contatos das interfaces eletrodos

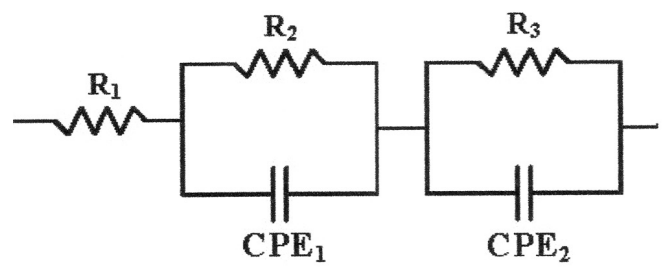

Figura 7. Circuito equivalente associado ao diagrama de impedância da Figura 6 
e o coletor de corrente, $\mathrm{Au}$ ); $\mathrm{R}_{2}$ e $\mathrm{R}_{3}$ são as resistências a altas e baixas frequências, respectivamente; $\mathrm{CPE}_{1}$ e $\mathrm{CPE}_{2}$ são elementos de fase constante, ${ }^{63}$ a altas e baixas frequências, respectivamente. O diagrama de impedância da Figura 6 apresenta dois semicírculos, um a altas e outro a baixas frequências. De acordo com a literatura estes fenômenos estão relacionados ao transporte de $\mathrm{O}^{2-}$ do TPB para o eletrólito (altas frequências) ou à difusão das espécies $\mathrm{O}^{-}$da superfície do eletrodo (frequências intermediárias). ${ }^{68}$

Devido à maior resistividade eletrônica do $\operatorname{LSM}\left(\sim 10^{-2} \Omega \mathrm{cm}\right.$ a $\left.800^{\circ} \mathrm{C}\right)$ em relação ao cermet $\mathrm{ZEI} / \mathrm{Ni}\left(\sim 10^{-4} \Omega \mathrm{cm}\right.$ a $\left.800^{\circ} \mathrm{C}\right)$, o catodo contribui de forma mais significativa para a resistência da célula. Assim, as medidas elétricas de meias células catodo/eletrólito e de células unitárias são importantes para se avaliar o desempenho das mesmas e, consequentemente, da pilha. ${ }^{22,63,65}$

De acordo com Kim e colaboradores, ${ }^{68}$ o seguinte mecanismo é proposto para as reações que ocorrem no catodo:

Etapa 1: $\mathrm{O}_{2}(\mathrm{~g}) \rightarrow 2 \mathrm{O}(\mathrm{ads})$

Etapa 2: $\mathrm{O}$ (ads) $+\mathrm{e}^{-} \rightarrow \mathrm{O}^{-}($ads $)$

Etapa 3: $\mathrm{O}^{-}$(ads) $\rightarrow \mathrm{O}^{-}$(TPB)

Etapa 4: $\mathrm{O}^{-}(\mathrm{TPB})+\mathrm{e}^{-} \rightarrow \mathrm{O}^{2-}(\mathrm{TPB})$

Etapa 5: $\mathrm{O}^{2-}(\mathrm{TPB})+\mathrm{V}_{\mathrm{o}} \cdot \boldsymbol{\bullet} \rightarrow \mathrm{O}^{\mathrm{x}}{ }_{\mathrm{o}}$

onde: $\mathrm{V}_{\mathrm{o}}$ • é uma vacância de oxigênio com duas valências e $\mathrm{O}_{\mathrm{o}}^{\mathrm{x}}$ é um íon oxigênio em um sítio iônico. ${ }^{69}$

Medidas de impedância de meias células catodo/eletrólito (LSM-ZEI/ZEI), realizadas por Kim e colaboradores ${ }^{68}$ mostram três semicírculos, a alta, intermediária e baixa frequências. O primeiro está relacionado ao transporte de $\mathrm{O}^{2-}$ do TPB para o eletrólito (etapa 5 do mecanismo), sendo que este semicírculo é pouco afetado pela pressão parcial de oxigênio. O semicírculo de frequências intermediárias diz respeito à difusão das espécies $\mathrm{O}^{-}$da superfície do LSM para o TPB (etapa 3). Já o de baixas frequências corresponde à difusão das moléculas de oxigênio nos poros do eletrodo ou à adsorção dissociativa do $\mathrm{O}_{2}$ (etapa 1).

Molinelli e colaboradores ${ }^{51}$ realizaram medidas de impedância a $800{ }^{\circ} \mathrm{C}$ para 2 células, unitárias com área ativa de $1 \mathrm{~cm}^{2}$, uma sem o interconector (depositado sobre o anodo de $10 \mathrm{~cm}^{2}$, Pt e malha de níquel como coletores de corrente) e a outra com interconector metálico $\left(10 \mathrm{~cm}^{2}\right)$. Foi observado que o desempenho em densidade de potência de ambas diferiu de um fator de 4, ou seja, $0,25 \mathrm{~A} / \mathrm{cm}^{2}$ (célula com interconectores) e $0,95 \mathrm{~A} / \mathrm{cm}^{2}$ (célula unitária), ambos a 0,7 V. A espectroscopia de impedância identificou claramente as causas dessa diferença, as quais foram relacionadas às perdas ôhmi-

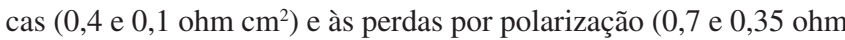
$\mathrm{cm}^{2}$ ). De acordo com Molinelli e colaboradores, o aumento da perda ôhmica é devido à contribuição adicional do interconector metálico, mostrando que a adição de novos materiais no empilhamento pode resultar em problemas no desempenho.

Lang et al. ${ }^{52}$ caracterizaram, eletroquimicamente, uma pilha ( $s t a-$ $c k$ ) de 1-5 células unitárias através da espectroscopia de impedância. Foi feito um estudo da influência da composição dos gases para a pilha operando a $800^{\circ} \mathrm{C}$ com as seguintes composições: $\mathrm{H}_{2}+\mathrm{N}_{2} / \mathrm{ar}, \mathrm{H}_{2}$ /ar, e $\mathrm{H}_{2} / \mathrm{O}_{2}$. A resistência ôhmica a altas frequências foi de $1,2-1,4$ $\Omega \mathrm{cm}^{2}$. A razão dos altos valores encontrados, em comparação com resultados obtidos por eles anteriormente, foi devido a problemas de contato na pilha. A impedância total, a baixas frequências, foi de $4,2 \Omega \mathrm{cm}^{2}$ utilizando $\mathrm{H}_{2} / \mathrm{O}_{2}$ e $4,6 \Omega \mathrm{cm}^{2}$ utilizando $\mathrm{H}_{2}+\mathrm{N}_{2} /$ ar. Já a resistência de polarização total foi de $2,8 \Omega \mathrm{cm}^{2}\left(\mathrm{H}_{2} / \mathrm{O}_{2}\right)$ e $3,3 \Omega$
$\mathrm{cm}^{2}\left(\mathrm{H}_{2}+\mathrm{N}_{2} / \mathrm{ar}\right)$. O diagrama de Nyquist mostrou 3 semicírculos: um a altas frequências, que representa a polarização do anodo, outro a frequências intermediárias, que corresponde à polarização do catodo e um terceiro a baixas frequências, que representa as reações eletroquímicas dos gases.

$\mathrm{O}$ anodo possuiu a mais baixa contribuição para a impedância total, devido a sua espessura e região de contato triplo otimizada.

Para a pilha a $800{ }^{\circ} \mathrm{C}$, em condição de potencial circuito aberto, o valor de impedância relacionado às reações dos gases foi de $1,4 \Omega$ $\mathrm{cm}^{2}\left(\mathrm{H}_{2} / \mathrm{ar}\right)$ e $1,7 \Omega \mathrm{cm}^{2}\left(\mathrm{H}_{2}+\mathrm{N}_{2} / \mathrm{ar}\right)$. $\mathrm{O}$ catodo apresentou as seguintes resistências de polarização: $0,9 \Omega \mathrm{cm}^{2}\left(\mathrm{H}_{2} / \mathrm{O}_{2}\right) ; 1,3 \Omega \mathrm{cm}^{2}\left(\mathrm{H}_{2}+\mathrm{N}_{2} /\right.$ ar) e $1,13 \Omega \mathrm{cm}^{2}\left(\mathrm{H}_{2} / \mathrm{ar}\right)$.

Lang e colaboradores também estudaram a influência da corrente no espectro de impedância. A resistência ôhmica a altas frequências diminuiu de $1,2 \Omega \mathrm{cm}^{2}$ (OCV) para $1,0 \Omega \mathrm{cm}^{2}\left(240 \mathrm{~mA} / \mathrm{cm}^{2}\right)$, resultando na diminuição da polarização total de $3,3 \Omega \mathrm{cm}^{2}$ (OCV) para $0,6 \Omega \mathrm{cm}^{2}\left(240 \mathrm{~mA} / \mathrm{cm}^{2}\right)$. Rp (catodo) passou de $1,2 \Omega \mathrm{cm}^{2}(\mathrm{OCV})$ para $0,33 \Omega \mathrm{cm}^{2}\left(240 \mathrm{~mA} / \mathrm{cm}^{2}\right)$ e Rp (anodo) passou de $0,6 \Omega \mathrm{cm}^{2}$ (OCV) para $0,2 \Omega \mathrm{cm}^{2}\left(240 \mathrm{~mA} / \mathrm{cm}^{2}\right)$. Os altos valores de $\mathrm{Rp}$ (anodo) ocorrem devido ao pobre contato entre as malhas de $\mathrm{Ni}$ e o anodo na célula unitária (cassette).

A pilha operou a $300 \mathrm{~mA} / \mathrm{cm}^{2}$ a $800{ }^{\circ} \mathrm{C} \mathrm{com} 1 \mathrm{lpm}$ (litro por minuto) $\mathrm{H}_{2}$ e $2 \mathrm{lpm}$ de ar por $1000 \mathrm{~h}$. Após $150 \mathrm{~h}$ de funcionamento a pilha atingiu a densidade de potência de $232 \mathrm{~mW} / \mathrm{cm}^{2}$ a $0,7 \mathrm{~V} ; 700 \mathrm{~h}$ mais tarde, a densidade de potência diminuiu para $156 \mathrm{~mW} / \mathrm{cm}^{2}$, com uma degradação de $30 \%$. Durante o funcionamento da pilha de 150 a 1000 h, a resistência ôhmica passou de 0,6 para $0,9 \Omega \mathrm{cm}^{2}$, devido à possível formação de óxido na superfície das placas metálicas dos interconectores que aumentou a resistência de contato. A análise microestrutural feita após os testes mostrou que o aumento da resistência ôhmica do anodo pode ter sido devido à sinterização do mesmo.

\section{GLOSSÁRIO}

Neste item são apresentadas, em ordem alfabética, possível traduções do inglês para o português e definições de alguns termos frequentemente empregados na área das PaCOS.

Area specific resistance - REA (Resistência específica por área): parâmetro utilizado para avaliar o desempenho das PaCOS. Corresponde à diferença entre o potencial medido nas condições de operação da pilha e o potencial de Nernst, dividida pela densidade de corrente.

Bipolar plates (Placas bipolares ou interconectores): placas cerâmicas ou metálicas usadas entre as células unitárias para distribuir os gases, no empilhamento.

Cassette (cassete): é a combinação de um interconector; um gasket e uma célula unitária. Unidade básica de repetição na pilha.

Co flow (fluxo paralelo de mesmo sentido): tipo de configuração em que os gases combustível e oxidante fluem no mesmo sentido e direção.

Computational Fluid Dynamics - CFD (Dinâmica de fluidos computacional): conjunto de técnicas que visa modelar, numericamente, o escoamento dos fluidos.

Counter flow (fluxo paralelo de sentido contrário): tipo de configuração em que os gases combustível e oxidante fluem na mesma direção, porém em sentido contrário.

Cross flow (fluxo cruzado): tipo de configuração em que os gases combustível e oxidante fluem em sentido e direção contrários.

Current density: densidade de corrente, valor da corrente dividida pela área ativa da célula.

Dry air: ar sem umidificação $\left(\mathrm{H}_{2} \mathrm{O}\right)$.

Degradation: degradação do desempenho da célula, durante a operação. 
Endplate (Placa de base e de topo): placas feitas, em geral, do mesmo material que o interconector e que estão na base e no topo do empilhamento.

External supporting (Suporte externo): configuração da célula, na qual a mesma utiliza como suporte um componente externo (interconector ou substrato poroso).

Felt (Feltro): é uma "malha" ou "feltro" usada entre os eletrodos e interconector para melhorar o contato elétrico. Pode ser feito de materiais como Ni ou Inconel.

Flow rate: taxa de fluxo dos gases.

FEM (Finite Element Method): análise por elementos finitos. Técnica que possibilita a resolução de uma equação diferencial parcial que pode modelar um fenômeno físico e/ou químico.

Ferritic stainless steel: aço inoxidável de microestrutura ferrítica, possível material utilizado como interconectores.

Fins (Aletas): conduzem a corrente coletada na superfície da célula.

Flow cannels (canais de fluxo): região entre duas aletas, responsável para distribuir o gás ao longo da pilha.

Gasket (retentor de gás): placa auxiliar para vedação de gases, geralmente feita do mesmo material que o interconector.

Gas separation frame (quadro de separação de gás): mesmo que gasket.

Gas tightness (Estanque): Algo que é estanque e/ou hermético à passagem de gás.

Inconel: família de ligas metálicas à base de níquel. Inconel é um marca registrada.

Intermediate plates: interconectores (placas) intermediários utilizados no empilhamento para conectar uma célula a outra.

LSM (manganita de lantânio dopada com estrônico - $\mathrm{Sr}_{\mathrm{x}} \mathrm{La}_{1}$. $\mathrm{MnO}_{3-\delta}$ usualmente com $\mathrm{x}$ entre 0,15 e 0,50). Material mais empregado em catodo das PaCOS.

Manifold (distribuidor de vazão ou coletor): região do interconector que conduz o fluxo dos gases da entrada do interconector aos canais de fluxo.

Mesh (malha): O mesmo que Felt.

Metal plates: placas metálicas usadas como interconectores no empilhamento.

$\mathrm{Ni} / \mathrm{YSZ}\left(\mathrm{Ni} / \mathrm{ZrO}_{2}-\mathrm{Y}_{2} \mathrm{O}_{3}\right), \mathrm{ZEI} / \mathrm{Ni}$ : compósito cerâmico de níquel e zircônia estabilizada com ítria, atualmente, mais empregado como material de anodo das PaCOS.

PaCOS (Pilha a combustível de óxido sólido): conjunto de várias células unitárias.

Performance: desempenho da pilha ou célula unitária, gerado durante o funcionamento.

Reformer (reformador): extrai o hidrogênio de combustíveis, como os hidrocarbonetos, para serem utilizados nas células a combustível.

Screen printing (Impressão de serigrafia): equipamento usado para a deposição de filmes finos ou espessos, porosos ou não, de pequenas ou grandes extensões e com elevada definição.

Sealant (selante): material vítreo ou vitro-cerâmico ou compósito à base de mica usado para conectar as células unitárias no empilhamento.

Self supporting (célula suportada por um dos seus componentes): tipo de configuração da célula na qual o suporte é um dos componentes da mesma, como catodo, anodo ou eletrólito.

SOFC (Solid Oxide Fuel Cell): célula a combustível de óxido sólido que opera a altas temperaturas $\left(800-900{ }^{\circ} \mathrm{C}\right)$.

Spray coating (aerografia): técnica utilizada para a deposição de filmes finos porosos ou não.

Stack (empilhamento): associação de várias células unitárias.

Stack output: potência gerada pelo empilhamento.
Stress (tensão mecânica): tensão mecânica gerada por forças aplicadas sobre uma determinada área. É ocasionado por componentes acoplados que apresentam diferentes coeficientes de expansão térmica.

STS (Stainless Steel): aço inoxidável, material geralmente empregado como interconectores das PaCOS.

Tape casting (colagem de folhas cerâmicas): técnica utilizada para conformar em fitas as barbotinas de material cerâmico. Usado para preparar filmes porosos de anodo e densos de eletrólito.

$T P B$, Triple boundary phase (região de contato triplo): região onde se encontram o eletrodo, o eletrólito e o gás. É onde ocorrem as reações eletroquímicas.

Voltage: tensão, em volts (V).

YSZ: $\mathrm{ZrO} / \mathrm{Y}_{2} \mathrm{O}_{3}$ (Zircônia estabilizada com ítria-ZEI): material utilizado como eletrólito das células a combustível de óxido sólido.

\section{CONCLUSÃO}

Nessa revisão procurou-se realizar uma abordagem, sobretudo acadêmica, das dificuldades e soluções experimentais encontradas na montagem e caracterização elétricas de Pilhas a Combustível de Óxidos Sólido de configuração do tipo planar.

O estado da arte dos interconectores, dispositivos que possuem um papel importante no empilhamento das células unitárias, foi apresentado, abordando principalmente os principais problemas e limitações desses componentes no empilhamento e no funcionamento das PaCOS.

A partir de exemplos da literatura e de trabalhos realizados em nosso laboratório, foram discutidos procedimentos empregados nas caracterizações elétricas e eletroquímicas das PaCOS através, principalmente, da técnica de espectroscopia eletroquímica de impedância e de medidas de densidade de potência em função da densidade de corrente.

Atualmente a configuração das células unitárias suportada pelo anodo se mostra mais eficiente, comparada com a célula suportada pelo eletrólito, devido à sua menor resistência ôhmica e por apresentar melhor difusividade do $\mathrm{H}_{2}$ em relação ao $\mathrm{O}_{2}$ até a interface anodo/ eletrólito. A densidade de potência para uma célula unitária suportada pelo anodo varia de 0,18 a $10 \mathrm{~W} \mathrm{~cm}^{-2}$, de acordo com exemplos citados neste artigo. Numa célula unitária suportada pelo eletrólito, construída pelo LAMPAC, a maior densidade de potência foi de 2,5 $\mathrm{mW} \mathrm{cm}{ }^{-2}$, obtida com fluxo de $\mathrm{H}_{2}$ de $250 \mathrm{~mL} \mathrm{~min}^{-1}$ e de ar de 500 $\mathrm{mL} \min ^{-1} \mathrm{a} 800{ }^{\circ} \mathrm{C}$. Entretanto, em temperaturas mais elevadas, a densidade de potência deste tipo de célula pode atingir $10 \mathrm{Wcm}^{-2}$, de acordo com a literatura.

Foi apresentado, ainda, um glossário inglês-português contendo os termos mais empregados no empilhamento das PaCOS, com objetivo de proporcionar maior clareza ao texto e introduzir termos relativamente novos ao leitor.

\section{AGRADECIMENTOS}

À CEMIG e ao CNPq pelo apoio financeiro.

\section{REFERÊNCIAS}

1. Florio, D. Z. de; Fonseca, F. C.; Mucillo, E. N. S; Muccillo, R.; Cerâmica 2004, 50, 275.

2. Amado, R. S.; Malta, F. B.; Garrido, F. M. S.; Medeiros, M. E.; Quim. Nova 2007, 30, 189; Takehisa, F.; Kenji, M.; Satoshi, O.; Hiroya, A.; Makio, N.; Kiyoshi, N.; J. Power Source 2004, 125, 17; Li, J.; Zhe, L.; Jipeng, M.; Zhiguo, L.; Guoqing, L.; Wenhui, S.; J. Alloys Compd. 2006, 414, 152.

3. Went, H.; Götz, M.; Linardi, M.; Quim. Nova 2000, 23, 538.

4. Went, H.; Linardi, M.; Aricó, E. M.; Quim. Nova 2002, 25, 470.

5. Schlapbach, L.; Züttel; A.; Nature 2001, 414, 353

6. Mihn, N. Q.; Solid State Ionic 2004, 174, 271. 
7. http://www.celulaacombustível.com.br, acessada em Março 2007.

8. http://www.fuelcellsworks.com/Typesoffuelcells.html, acessada em Novembro 2008.

9. Programa Brasileiro de Células a Combustível-PROCaP. Diário Oficial da República Federativa do Brasil, Poder Executivo, Brasília, 2004.

10. http://www.redepacos.coppe.ufrj.br, acessada em Novembro 2008.

11. Florio, D. Z.; Varela, J. A.; Fonseca, F. C.; Muccillo, E. N. S.; Muccillo, R.; Quim. Nova 2007, 30, 1339.

12. Wendt, H.; Spinacé, E. V.; Neto, A. O.; Linardi, M.; Quim. Nova 2005, $28,1066$.

13. Gonzalez, E. R.; Quim. Nova 2000, 23, 262.

14. Spinacé, E. V.; Neto, A. O.; Franco, E. G.; Linardi, M.; Quim. Nova 2004, 27, 648 .

15. Benjamin, T. G.; Camara, E. H.; Marianowski, L.G.; Handbook of Fuel Cell Performance, $6^{\text {th }}$ ed., Morgantown WV, 2002.

16. Minh, N. Q.; J. Am. Ceram. Soc. 1993, 76, 563.

17. Zhu, W. Z.; Deevi, S. C.; Mater. Sci. Eng. A 2003, 348, 227.

18. Badwal, S. P. S.; Solid State Ionics 2001, 143, 39.

19. Yoshida, H.; Yakabe, H. K.; Ogasawara, T. S.; J. Power Sources 2006, 157,775 .

20. Anderson, H. U.; Murphy, R.; Humphrey, K. R. B.; Aldred A.; Procarioue, W. L.; Ackermann, R. J.; Proceeding of the The Rare Earths in Modern Science and Technology, New York, 1978.

21. Kononyuk, I. F.; Tolochko, S. P.; Surmach, N. G.; Materia 1986, 22, 98.

22. Singhal, S. C.; Kendall, K.; High Temperature Solid Oxide Fuel Cells: Fundaments, Design and Applications, Elsevier: Oxford, 2003.

23. Zhien, L.; Barrienger, E.; Goettler. R.; Nature 2001, 414, 345.

24. Bae, J.; Lim, S.; Jee, H.; Kim, J. H.; Yoo, Y. S.; Lee, T.; J. Power Sources 2007, 172,1 00.

25. Hilpert, K. D.; Miller, M.; Peek, D. H.; Weib, R.; J. Eletrochem. Soc. 1996, 143, 297.

26. Jung, H. Y.; Choi, S-H.; Kim, H.; Son, J-W.; Kim, J.; Lee, H-W.; Lee, J.-H.; J. Power Sources 2006, 159, 478.

27. Leng, Y. J.; Chan, S. H.; Khor, K. A.; Jiang, S. P.; Cheang, G. P. C.; J. Power Sources 2003, 117, 26.

28. Jian, L.; Jian, P.; Guangyuan, X.; Shunxu, W.; Jianzhong, X.; J. Power Sources 2005, 139, 182.

29. Deng, X.; Wei, P.; Bateni, M. R.; Petric, A.; J. Power Sources 2006, 160, 1225.

30. Kima, J-H.; Songa, R-H.; Hyunb, S-H.; Solid State Ionics 2004, 174, 185.

31. Qua, W.; Jian, L.; Hill, J. M.; Ivey, D. G.; J. Power Sources 2006, 138, 162.

32. Dekker, N.; Rietveld, B.; Laatsch, J.; Tietz, F.; Proceeding of the sixth European SOFC Forum, Lucerne, Switzerland, 2004.

33. Gubner, A.; Xuan, T. N. X.; Bram, M.; Remmel, J. H. L. G. J.; Proceeding of the seventh European SOFC Forum, Lucerne, Switzerland, 2006.

34. Konysheva, E.; Laatsch, J., Wessel, E.; Tietz, F.; Christiansen, N.; Singheiser, L.; Hilpert, K.; Solid State Ionics 2006, 177, 923.

35. Sakai, N.; Yamaji, K.; Horita, T.; Yokokawa, H.; Uehara, T.; Toji, A.; Kameda, H.; Ogosawara, K.; Matsuzaki, Y.; Sakurai, T.; Proceeding of the seventh European SOFC Forum, Lucerne, Switzerland, 2006.

36. Schmidt, M.; Fuel Cells Bull. 1998, 1, 9.

37. Batfalsky, P.; Haanappel, V. A. C.; Malzbender, J.; Menzler, N. H.; Shemet, V.; Vinke, I. C.; Steinbrech, R. W.; J. Power Sources 2006, 155, 128

38. Badwal, S. P. S.; Deller, R.; Foger, K.; Ramprakash, Y.; Zhang, J. P.; Solid State Ionics 1997, 99, 297.

39. Lim, D. P.; Oh, D. S.; Lim, J. S.; Lyo, I. W.; Surf. Coat. Technol. 2005, 200,1251

40. Chen, X.; Hou, P. Y.; Jacobson, C. P.; Visco, S. J.; Johghe, L. C. D.; Solid State Ionics 2005, 176, 425.
41. Chen, L.; Yang, Z.; Jha, B.; Xia, G.; Stevenson, J. W.; J. Power Sources $\mathbf{2 0 0 5}, 152,40$.

42. Shaigan, N.; Ivey, D. G.; Chen, W.; J. Power Sources 2008, 185, 331.

43. Montero, X.; Tietz, F.; Sebold, D.; Buchkremer, H. P.; Ringuede, A.; Cassir, M.; Laresgoiti, A.; Villareal, I.; J. Power Sources 2008, 184, 172.

44. Fontana, S.; Amendola, R.; Chevalier, S.; Piccardo, P.; Caboche, G.; Viviani, M.; Molins, R.; Sennour, M.; J. Power Sources 2007, 171, 652.

45. Tanner, C. W.; Vikar, A. V.; J. Power Sources 2003, 113, 44.

46. Singnal, S. C.; Dokiya, M.; Yamamoto, O.; Tagawa, H.; Singnal, S. C.; J. Electrochem. Soc. 1993, 95, 195.

47. Sammes, N. M.; Du, Y.; Bove, R.; J. Power Sources 2005, 145, 428.

48. Badwal, S. P. S.; Foger, K.; Ceram. Int. 1996, 22, 257.

49. Dokiya, M.; Honolulu; Singhal, S. C.; Proc. $6^{\text {th }}$ Int. Symp. Solid Oxide Fuel Cells, Hawaii, 1999.

50. Wen, T-L.; Wang, D.; Tu, H. Y.; Chen., M.; Lu, Z.; Zhang, Z.; Nie, H.; Huang, W.; Solid State Ionics 2002, 152, 399.

51. Molinelli, M.; Larrain, D.; Autissier, N.; Ihringer, R.; Sfeir, J.; Badel, N.; Bucheli, O.; Herle, J. V.; J. Power Sources 2006, 154, 394

52. Lang, M.; Auer, C.; Eismann, A.; Szabo, P.; Wagner, N.; Electrochim. Acta 2008, 53, 7509.

53. Suwanwarangkul, R.; Croiset, E.; Pritzker, M. D.; Fowler, M. W.; Douglas, P. L.; Entchev, E.; J. Power Sources 2006, 154, 74.

54. Yamahara, K.; Jacobson, C. P.; Visco, S. J.; Jonghe, L. C. D.; Solid State Ionics 2005, 176, 451

55. Yokoo, M.; Tabata, Y.; Yoshida, Y.; Hayashi, K.; Nozaki, N.; Nozawa, K.; Arai, H.; J. Power Sources 2008, 178, 59; Yokoo, M.; Tabata, Y.; Yoshida, Y.; Hayashi, K.; Nozaki, N.; Nozawa, K.; Arai, H.; J. Power Sources 2008, 184, 84.

56. Yang, K.; Shen, J. H.; Yang, K. Y.; Hung, I. M.; Fung, K. Z.; Wang, M. C.; J. Power Sources 2006, 159, 63.

57. Liu, Y.; Hashimoto, S.; Nishino, H.; Takei, K.; Mori, M.; J. Power Sources 2007, 164.

58. Jiang, S. P; Badwal, S. P. S.; Solid State Ionics 1999, 123, 209.

59. Godoi, G. S.; Souza, D. P. F.; Mater. Sci. Eng. B 2007, 140, 90.

60. Reitz, T. L.; Xiao, H.; J. Power Sources 2006, 161, 437.

61. Muccillo, R.; Muccillo, E. N. S.; Fonseca, F. C.; França, Y. V.; Porfirio, T. C.; Florio, D. Z. de; Berton, M. A. C.; Garcia, C. M.; J. Power Sources 2006, 156, 455

62. http://www.fideris.com/Home;http://www.cfcl.com.au/Fuel_Cell_Test_ Systems/ http://www.hydrogenics.com, acessadas em Março 2007.

63. Macdonald, J. R.; Impedance spectroscopy: emphasizing solid materials and systems, Wiley: New York, 1987.

64. Huang, Q.-A.; Hui, R.; Wang, B.; Zhang, J.; Electrochim. Acta 2007, 52, 8144.

65. Domingues, R. Z.; Francisquini, G. C.; Brant, M. C.; Matencio, T.; Proceedings of the seventh European Solid Oxide Fuel Cell Forum, Lucerne, Switzerland, 2006; Cunha, F. T.; Domingues, R. Z.; Brant, M. C.; Fonseca, C. G.; Andrade, B. T.; Pinto, L. C. M.; Lameiras, F. S.; Matencio, T.; Proceedings of the seventh European Solid Oxide Fuel Cell Forum, Lucerne, Switzerland, 2006; Domingues, R. Z.; Basaglia, R. M. F.; Matencio, T.; Brant, M. C.; Proceedings of the seventh European Solid Oxide Fuel Cell Forum, Lucerne, Switzerland, 2006.

66. Bard, A.; Faulkner, L. F.; Electrochemical Methods: fundamentals and applications, New York, 1980.

67. Eco Chemie B. V.; Frequency Response Analysis for Windows - version 4.9.005; Ultrect, Holanda, 2004.

68. Kim, J. D.; Kim, G. D.; Moon, J. W.; Park, Y. I.; Lee, W. H.; Kobayashi, K.; Kagai, M.; Kim, C. E.; Solid State Ionics 2001, 143, 379

69. Déportes, C.; Duclot, M.; Fabry, P.; Fouletier, J.; Hammou, A.; Kleitz M.; Siebert, E.; Souquet, J. L.; Electrochimie des Solides, Presses Universitaires de Grenoble, 1994 